\title{
A Novel RFID EMSICC-based Chipless Tag
}

\author{
Soumaya SAKOUHI ${ }^{1}$, Hedi RAGGAD ${ }^{1}$, Ali GHARSALLAH ${ }^{1}$, Mohamed LATRACH ${ }^{2}$ \\ ${ }^{1}$ Dept. of Physics, Faculty of Sciences of Tunis, University of Tunis El Manar, 2092, Tunis, Tunisia \\ ${ }^{2}$ Radio-Freq. \& Microwave Research Group, ESEO 10 Boulevard Jeanneteau - CS 90717 - 49107 Angers Cedex 2, France \\ soumaya.sakouhi@fst.utm.tn
}

Submitted April 28, 2016 / Accepted October 18, 2016

\begin{abstract}
A new Radio Frequency Identification (RFID) chipless tag based on the Substrate Integrated Waveguide (SIW) technology is proposed in this paper. The tag highlights the importance of using such technologies allowing a surface miniaturization, a high $Q$-factor and an original shape. Thus, the novel design consists of an Eight-Mode Substrate Integrated Circular Cavity (EMSICC) associated to an Ultra Wideband (UWB) bowtie-shaped antenna. The EMSICC is realized by bisecting the Quarter Mode Substrate Integrated Circular Cavity (QMSICC) into two parts, while preserving the same resonant frequency and the original electric field distribution. Further, the operating frequency band is from $5 \mathrm{GHz}$ to $8 \mathrm{GHz}$ within a compact area of $4.97 \times 1.05 \mathrm{~cm}^{2}$. The proposed design is experimentally validated in the frequency domain.
\end{abstract}

\section{Keywords}

RFID, chipless tag, Substrate Integrated Waveguide (SIW), Substrate Integrated Circular Cavity (SICC), Half Mode SICC, Quarter Mode SICC, Eight-Mode Substrate Integrated Circular Cavity (EMSICC), EMS (Electromagnetic Signal)

\section{Introduction}

The RFID is a generic term for the identification using radio frequency waves. This wireless technology promises the advantages of tracking, identifying and data capturing by means of an RFID tag and an RFID reader.

The presence of a silicon chip in the tag makes it too expensive for applications in consumer products, and allows the RFID technology to be applied in just few fields, like the military, luggage handling in some airports as well as the toll and traffic management. In parallel, barcodes have been successfully accessed in industry over the past 20 years thanks to their low cost as compared to the RFID [1], [2].

For low cost and smart identification needs, the RFID chipless tag was the solution to dethrone its ancestor, the barcode, and works in parallel with the conventional RFID. It helps to meet the industrial needs for a smart RF barcode which benefits from the numerous innovative features of the conventional RFID and the low cost of the barcodes. The RFID chipless tag is passive, since it requires no electrical power and operates in read-only mode. It features the identification using RF waves, without a need to use a silicon chip (IC) to store data. Hence, with this challenging technology, the identifier (ID), which is the physical shape of a tag, is extracted from the tag EMS which depends only on its geometry. When it receives an incident EMS, the electromagnetic wave will create an EMS of its own. Then, this EMS will be reflected to the reader and used as an ID, as summarized in Fig. 1. Therefore, chipless tags can be classified according to their feeding mode, their operating frequency, as well as their physical structure that differs from one tag to another [3], [4].

We need to mention that chipless tags can be classified into different encoding techniques: frequency-domainbased tags [5], time-domain-based tags [6], phase-based tags [7] and image-based tags [8].

Based on these aforementioned encoding techniques, there are a hundred of different designs available in the literature. However, the only commercialized tag ever since has been the Surface Acoustic Wave (SAW) tag which is based on a time domain approach. It consists of a piezoelectric substrate and a SAW reflector which allows the signal attenuation. The SAW tag permits the encoding of 256 bits, but its cost is high due to its piezoelectric properties [9], [10]. Mainly, the frequency domain approach was the mostly used technique in the literature.

It is based on the control of the presence or absence of the resonances in the reading system bandwidth for particular frequencies allowing an improving data capacity and a short read range.

One can classify this approach into two different periods. The first period features the appearance of chipless tags, where research focuses essentially on improving data density. As for the second, it focuses on improving weight, size and encoding capacity by using different promising technologies in order to obtain the equation of size and performance. Starting from 2005, the first prototype of the 'RF barcode' consists of an array of 5 identical micro-strip dipoles where each dipole encodes 1 data bit [11], [12]. Besides, in 2009, another chipless tag was developed and it consists of 35 resonators associated to a transmitter and 


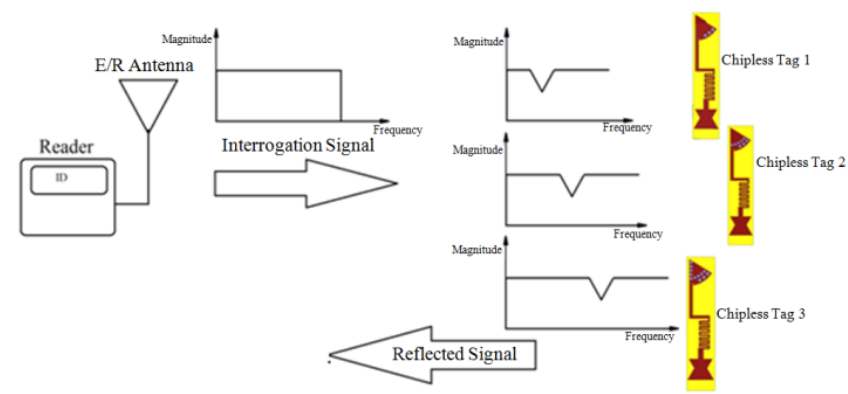

Fig. 1. Operation principle of EMSICC based chipless tag.

receiver antennas allowing an encoding capacity of 35 data bits [13]. In 2011, a new design consisting of a coplanar strip resonator making a ' $c$ ' shape and operating in the terahertz domain is presented, with an encoding capacity of 3.3 bits per $\mathrm{cm}^{2}$ [14]. From 2012, the second period has been triggered. In [15], a new chipless prototype is demonstrated based on a nested circular ring patch insensitive to the polarization. It provides a significant improvement in terms of detection and can reach 19 bits of the encoding capacity. Moreover, a chipless tag using the RF MEMS switch is proposed in [16], giving a reduced size and a distribution of 3 bits information over one period of the signal transmitted by an RFID reader. In [17], a 3-bit chipless tag is designed using a screen printing technique which enables a fast and thick tag production and exploits the frequency shift encoding proposed in [18] and [19]. The proposed chipless RFID tag is based on 3 dipoles like strips which are properly arranged at particular distances. Recently, in [20] and [21], a new concept of design is demonstrated based on the SIW technology. The tag encodes the data by changing the effective permittivity of the substrate integrated resonator which gives a unique frequency signature without any need to increase the tag size. Up to now, the RFID SIW-based chipless tag was not studied sufficiently.

In this paper, the SIW technology is used allowing the proposition of a novel chipless tag based on the EMSICC. The tag is designed, tested and validated to give us a compact size and a high quality factor using an effective miniaturization technique which enables the miniaturization of the tag to $1 / 8$ of its real size.

In Sec. 2, the basic principles of the EMSICC chipless tag are presented. The SICC, its Half-Mode, the QuarterMode and the Eight-Mode are simulated, designed, and measured. Besides, a bowtie UWB antenna is designed to be associated to the EMSICC. In Sec. 3, measurement results of the tag test are shown, and a comparison with some existing tags is finally discussed in Sec. 4.

\section{EMSICC-based Chipless Tag Behavior}

\subsection{Eight-Mode Substrate Integrated Circular Cavity}

The SIW is a promising technology which has been

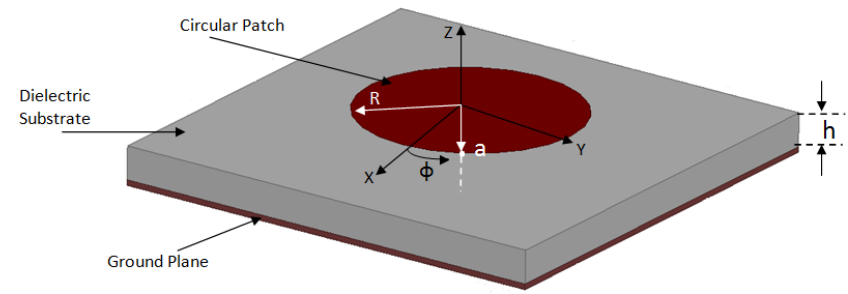

Fig. 2. The description of the circular cavity geometry.

widely employed in microwave components and circuit designs in order to reduce the fabrication complexity and facilitate its integration with planar circuits [22], [23]. Therefore, it is well known as a representative technique which performs the same functions as the rectangular waveguide. However, it has a much better integration density which makes it more compact. As a result it has been extensively studied in recent years. Also, many passive and active components based on the SIW technology have been designed and experimentally verified like filters [24], antennas [25], [26], couplers [27], oscillators [28], amplifiers [29], leaky-wave antennas and circulators [30], [31].

The choice of the SIW technology is not made at random since it offers various advantages, namely, high quality factor, low loss and ease of process fabrication. It also allows a significant reduction in size and weight which ensures the improvement of our chipless tag performance. In this section, a circular resonating cavity based on the SIW technology is studied. It consists of a circular patch and a circular row of metalized via connecting the solid metallic top and bottom plates. The circular cavity offers a number of radiation pattern options which are not readily founded using a rectangular cavity.

The radius $R$ has a driving point location at $a$, and makes an angle $\phi$ with an axis $x$, as shown in Fig. 2 . Then, the electric field in the circular cavity is described as follows:

$$
E_{\mathrm{Z}}=E_{0} \mathrm{~J}_{n}(k a) \cos (n \phi) .
$$

The magnetic field components are described as follows:

$$
\begin{aligned}
& H_{\mathrm{a}}=-\frac{\mathrm{j} \omega \varepsilon n}{k^{2} a} E_{0} \mathrm{~J}_{n}(k a) \cos (n \phi), \\
& H_{\phi}=-\frac{\mathrm{j} \omega \varepsilon}{k} E_{0} \mathrm{~J}_{n}^{\prime}(k a) \cos (n \phi)
\end{aligned}
$$

where $k$ is the propagation constant in the dielectric which has a constant $\varepsilon=\varepsilon_{0} \varepsilon_{\mathrm{r}}$ and $\mathrm{J}_{n}$ is the Bessel function of the first kind of order $n . \mathrm{J}_{n}{ }^{\prime}$ is the derivative of Bessel function with respect to its argument and $\omega$ is the angular frequency $(\omega=2 \pi f)$.

Further, the open-circuited edge condition requires that $\mathrm{J}_{n}{ }^{\prime}(k R)=0$, and for each mode of a circular cavity there is an associated radius which depends on the zeros of the derivative of the Bessel function. Bessel functions in this analysis are analogous to sine and cosine functions in the rectangular coordinates. $E_{0}$ is the value of the electric field at the edge of the patch across the gap [32]. 


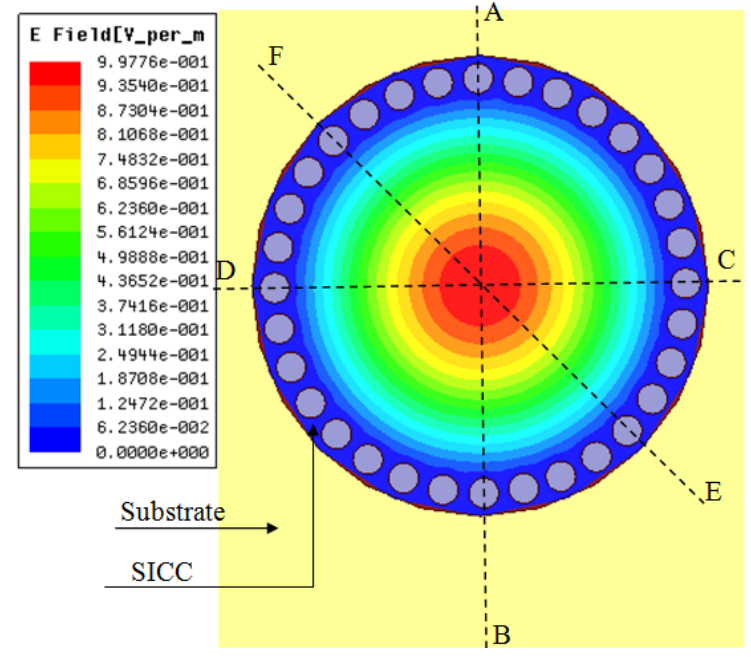

Fig. 3. Electric field distribution of the SICC.

Figure 3 shows the electric field distribution in the circular SIW cavity simulated on Ansoft HFSS.

The maximum electric fields are concentrated inside the cavity limited by the metalized via and symmetric along all planes (AB, CD and $\mathrm{EF})$.

$\mathrm{TM}_{010}$ is selected as the operating mode in the SICC. When the SICC height and radius meet with $h<2.1 R$, the corresponding resonant frequency of the $\mathrm{TM}_{010}$ mode for the SICC is:

$$
f_{010}=\frac{0.383 c}{R \sqrt{\varepsilon_{\mathrm{r}}}}
$$

where $c$ is the speed of light in a free space, $R$ is the radius of the SICC, and $\varepsilon_{\mathrm{r}}$ is the relative permittivity of the substrate.

Our SICC is a metal disk with a radius of $R=10.75 \mathrm{~mm}$ and metalized via which are arranged with a spacing angle of $p=11.25^{\circ}$, as shown in Fig. 4(a). The cavity presents a notch with a length of $n_{\mathrm{s}}=4.26 \mathrm{~mm}$.
Moreover, it was designed to operate at a frequency of $5.8 \mathrm{GHz}$, on an FR4 substrate with $\varepsilon_{\mathrm{r}}=4.6$ and with a thickness of $h=0.8 \mathrm{~mm}$.

The distribution of the $\mathrm{TM}_{010}$ mode inside the SICC proved that electric fields are symmetric along $\mathrm{AB}, \mathrm{CD}$ and EF planes, and each plane can be considered as an equivalent magnetic wall.

Consequently, and along the AB plane, the SICC can be bisected into two semi-SICCs. Each half is called Half Mode SICC(HMSICC), which enables size reduction by half, with conservation of the original distribution of electric field. Further, along the $\mathrm{CD}$ plane, and when dividing the HMSICC into two parts, the QMSICC is obtained offering the quarter of the cavity size. In order to obtain the main structure in our study, bisecting the QMSICC into two semi-quarter SICCs through the EF symmetric plane allows getting the Eight Mode Substrate Integrated Circular Cavity (EMSICC) which has practically the same electric field distribution as that of the SICC, the HMSICC and the QMSICC.

The size of the EMSICC is then $1 / 8$ of the SICC with an identical resonant frequency as proved in Fig. 4 with the evolution process to obtain the miniaturized cavity. The configuration of the EMSICC is shown in Fig. 4(d) with a width of $W_{\mathrm{EM}}=10.5 \mathrm{~mm}$, and a length of $L_{\mathrm{EM}}=17 \mathrm{~mm}$. $d_{2}=1 \mathrm{~mm}$ is the distance between the edge and the cavity shape, and $n_{\mathrm{s}}=1.052 \mathrm{~mm}$ represents the cavity notch length. The spacing by millimeter between the 2 metalized vias is $s=1.89 \mathrm{~mm}$, and the diameter of the via is $d_{1}=1.4 \mathrm{~mm}$. Moreover, a 50-Ohm microstrip is designed as a feeding line which allows the measurements of the EMSICC and permits to connect the EMSICC to the antenna in order to form the complete chipless tag.

It operates in a sub band of the UWB from $5 \mathrm{GHz}$ to $8 \mathrm{GHz}$, giving a resonant peak in $5.8 \mathrm{GHz}$ as the SICC, the HMSICC and the QMSICC. Figure 5 shows the 4 cavity responses and as already seen, the resonant peak of the

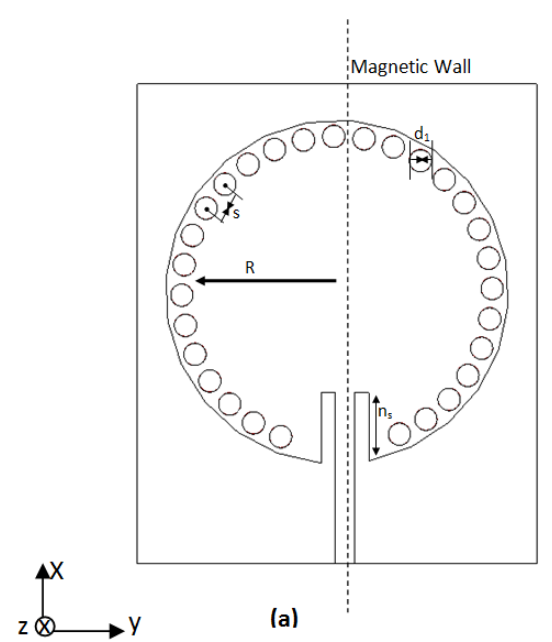

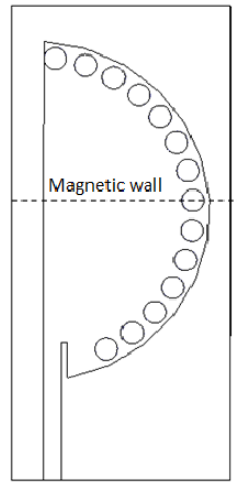

(b)

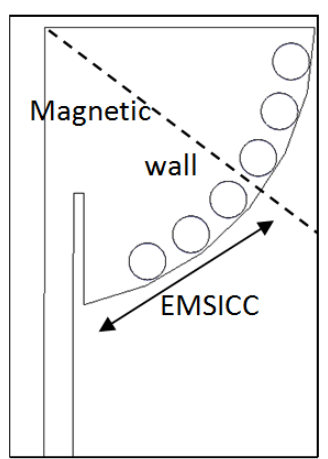

(c)

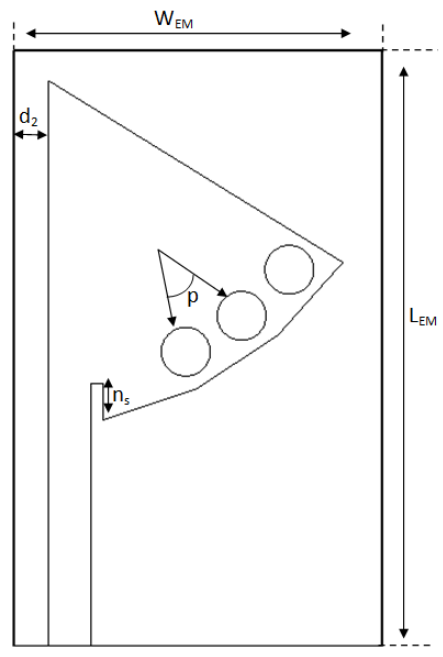

(d)

Fig. 4. Evolution process of the proposed EMSICC-based tag: a) SICC structure, b) HMSICC c) QMSICC, d) EMSICC. 


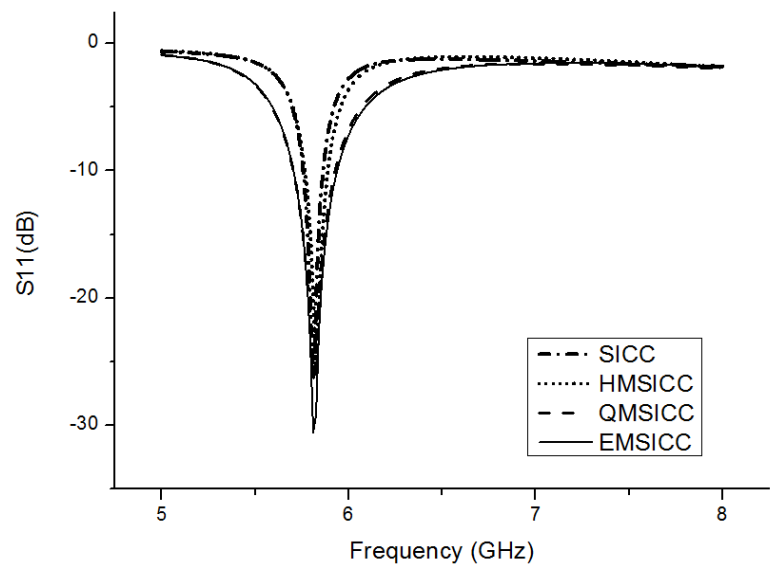

Fig. 5. Simulated S11 response using four different configurations.
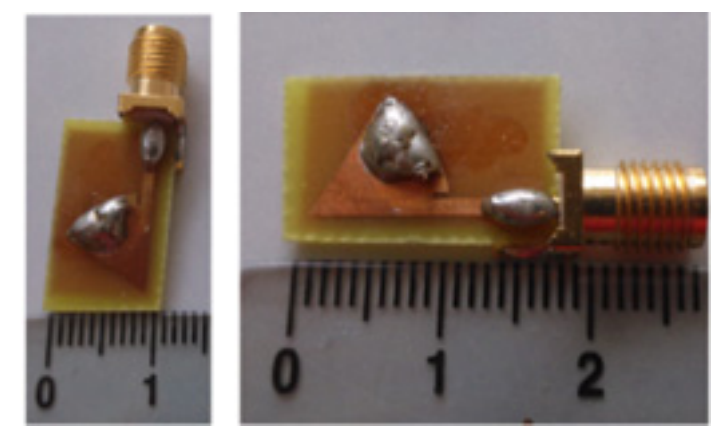

Fig. 6. Prototype photograph of the EMSICC configuration.

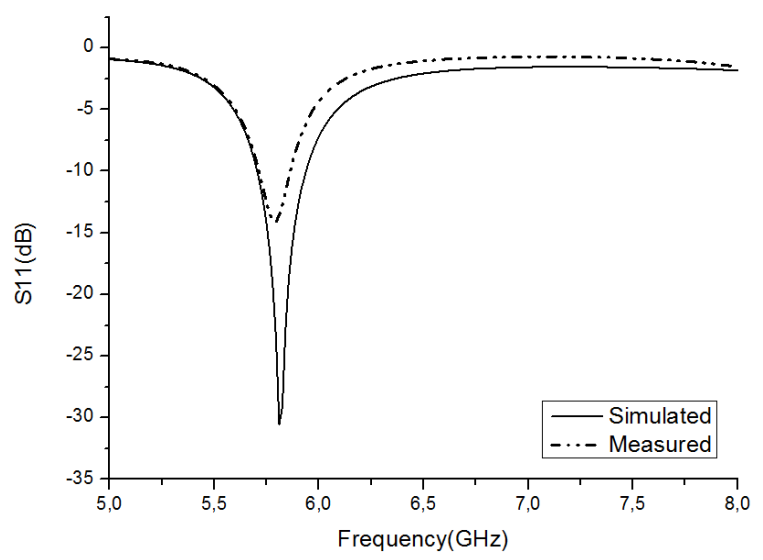

Fig. 7. Simulated and measured responses of the EMSICC configuration.

four configurations is the same with a slight difference in the bandwidth.

The EMSICC prototype is shown in Fig. 6. Also, a good return loss characteristic is obtained at the operating frequency which exhibits a quality factor equal to 264 at a frequency of $5.81 \mathrm{GHz}$. Therefore, the measurement is realized using the Agilent technology N5247A PNA-X network analyzer which covers the frequency range of $10 \mathrm{MHz}$ to $67 \mathrm{GHz}$.

The comparison between the measured and simulated responses of the EMSICC shows a good agreement, as shown in Fig. 7. Besides, the measured return loss has a lower adaptation due to the fact that the via metallization is done manually.

In this model, the EMSICC is the encoding area of our chipless tag. The frequency domain approach is here adopted as an encoding approach using a simple frequency shifting technique which depends on the position and the nature of the via (air via or metalized via) inside the cavity substrate.

Accordingly, for each missing air via inside the substrate integrated cavity resonator in [20], the frequency is decreased by $0.1 \mathrm{GHz}$.

In this work, adding the air via one by one allows a low frequency shift of $0.06 \mathrm{GHz}$. For example, adding the first air via allows obtaining a resonant peak at $5.75 \mathrm{GHz}$. Hence, a second air via shifts the frequency to $5.69 \mathrm{GHz}$. In the other hand, adding a row of four via holes engenders a decrease in frequency of around $0.3 \mathrm{GHz}$ and $5.57 \mathrm{GHz}$. This leads to the conclusion that via holes slightly shift the frequency. Also, adding a second row of air via perpendicular to the first increases the frequency to $6 \mathrm{GHz}$, as shown in Fig. 8 which describes the encoding area and its different constituents.

Hence, to achieve a major shift frequency, we can replace the air holes by metalized vias. Starting with the first row, metalizing the first air hole gives a significant shift of 6.7 GHz, while metalizing the second gives a greater shift of $7.13 \mathrm{GHz}$. Thus, metalizing the third air via shifts the frequency to $7.55 \mathrm{GHz}$.

As seen below, the EMSICC can guarantee the shifting technique mainly with an air via diameter of $d_{\text {air }}=1.2 \mathrm{~mm}$, an angular pitch of $P_{1}=10^{\circ}$ and a spacing between the two air vias of the second row of $S_{1}=1.5 \mathrm{~mm}$.

Hence, the measured and simulated responses of different encoding states of the EMSICC show a very good agreement, as seen in Fig. 9 which in turn validates our design.

Subsequently, it is important to mention that the relative permittivity of the FR4 substrate varies significantly

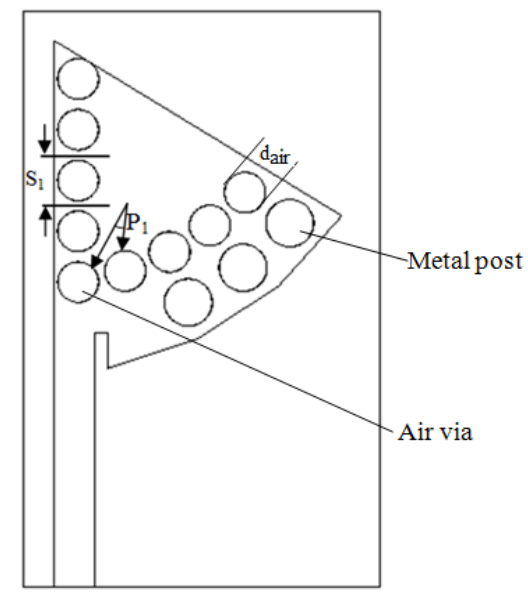

Fig. 8. Shifting technique based EMSICC. 


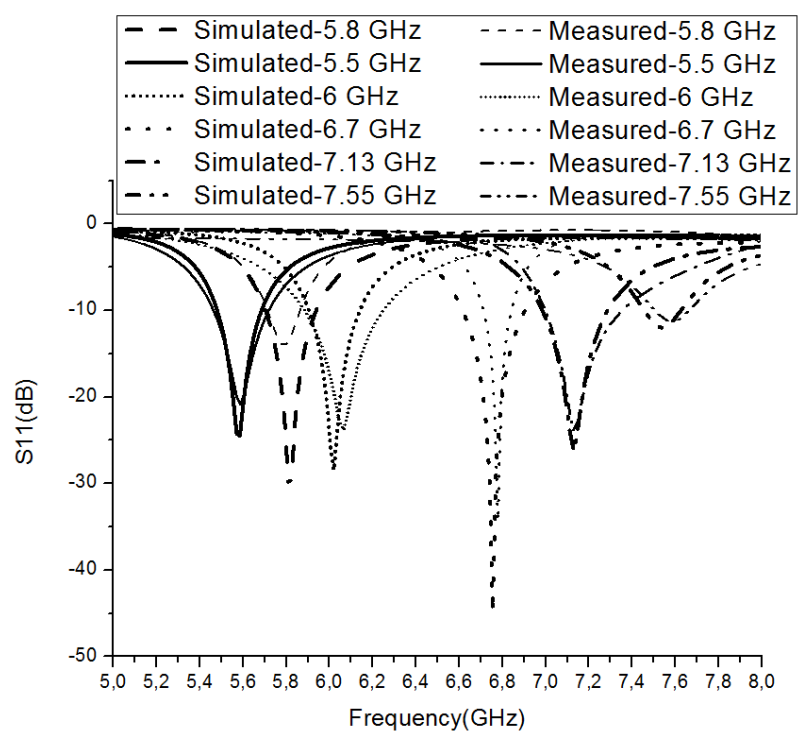

Fig. 9. Simulated and measured return los response using the shifting encoding technique.

with frequency, with fiberglass and with resin contents, which is an important topic and has a significant impact on measurement results in our case, if there are substantial changes in the material parameters.

So, if the necessary information on materials parameters is inaccessible in knowledge bases, the relative permittivity at the assumed frequency band should be determined experimentally using some methods as $\mathrm{T}$ and modified ring resonator technique detailed in [33].

\subsection{Bowtie-shaped Antenna-based Chipless Tag}

The second part of our chipless tag is the UWB antenna. The chosen structure is a bowtie shaped antenna that ensures the wideband operation. We used the same FR4 substrate as used for EMSICC. The tag antenna is

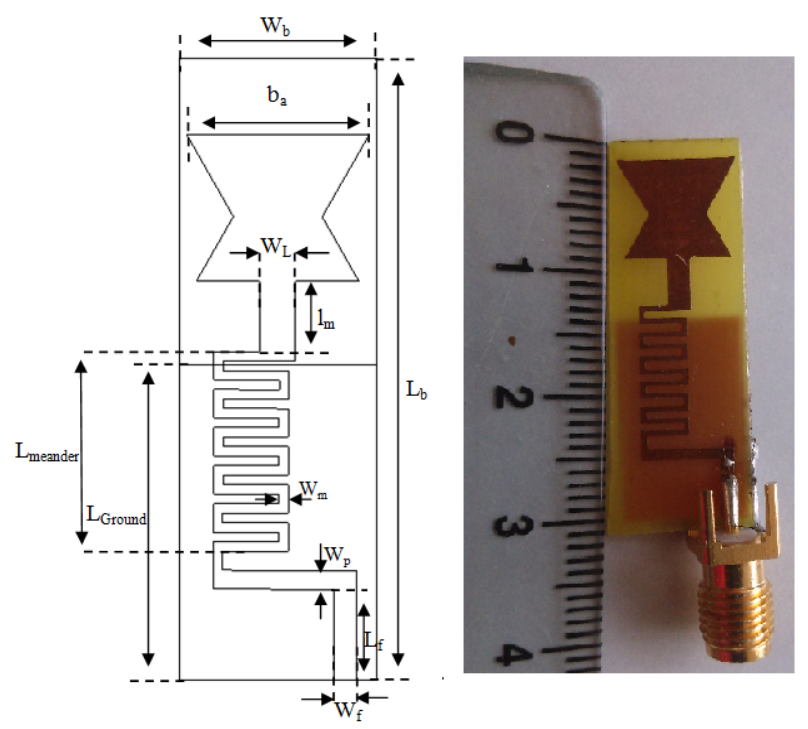

Fig. 10. Photograph of the chipless tag antenna.

\begin{tabular}{|c|c|}
\hline Symbol & Value (mm) \\
\hline $\boldsymbol{L}_{\mathrm{b}}$ & 32.7 \\
\hline $\boldsymbol{W}_{\mathrm{b}}$ & 10.5 \\
\hline $\boldsymbol{b}_{\mathrm{a}}$ & 9.7 \\
\hline $\boldsymbol{W}_{\mathbf{L}}$ & 1.9 \\
\hline $\boldsymbol{l}_{\mathrm{m}}$ & 3.7 \\
\hline $\boldsymbol{W}_{\mathrm{m}}$ & 0.5 \\
\hline $\boldsymbol{W}_{\mathrm{p}}$ & 1.2 \\
\hline $\boldsymbol{L}_{\mathrm{f}}$ & 4.8 \\
\hline $\boldsymbol{W}_{\mathbf{f}}$ & 1.2 \\
\hline $\boldsymbol{L}_{\text {Ground }}$ & 16.6 \\
\hline $\boldsymbol{L}_{\text {meander }}$ & 10.5 \\
\hline
\end{tabular}

Tab. 1. Dimensions of the bowtie shaped antenna.

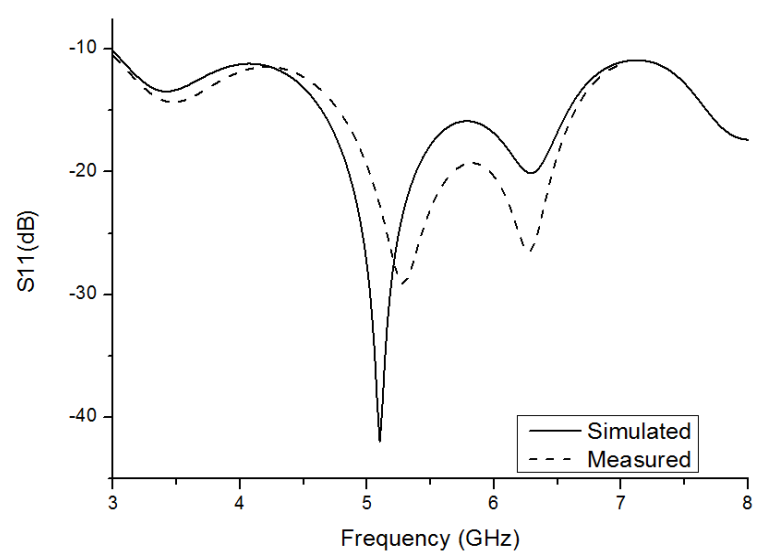

Fig. 11. Simulated and measured return loss of the bowtie shaped antenna.

simulated, optimized and finally designed as shown in Fig. 10 using the design parameters shown in Tab. 1. It presents some meanders lines which help to extend the band and have an UWB antenna.

Also, the antenna gain is about $1.1 \mathrm{dBm}$. This is an acceptable result because it is proposed for near-field applications.

Figure 11 shows the measured return loss of the proposed antenna with a matching above $10 \mathrm{~dB}$ from $3.1 \mathrm{GHz}$ to $8 \mathrm{GHz}$.

\section{Chipless Tag Association}

The association step is the main part that will result in an RFID chipless tag based on an EMSICC and an UWB bowtie antenna. The whole size of the tag is about $4.9 \times 1.05 \mathrm{~cm}^{2}$. In this section, we analyze the system performance. Our prototype is shown in Fig. 12. which also shows that the metallization is done manually at the beginning. It is characterized by a compact size and an original shape and it can be inserted in credit cards or personal ID cards thanks to its reduced thickness.

To validate the design of the proposed EMSICC based tag, 6 chipless tags configurations were tested. Each tag has been interrogated separately to identify its signature. 


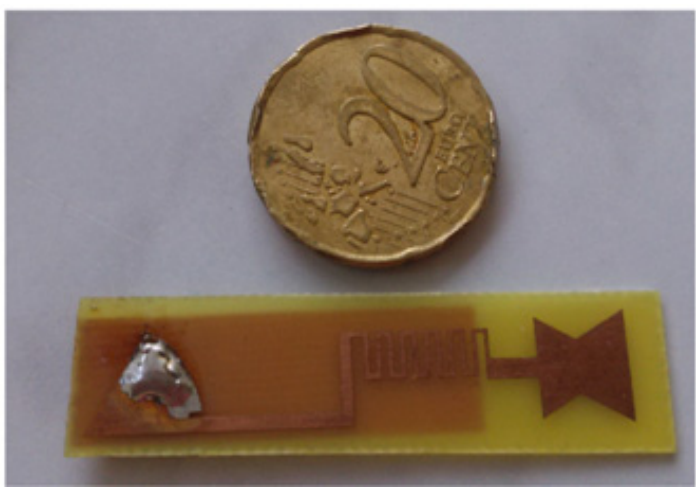

Fig. 12. Photograph of the EMSICC based chipless tag.

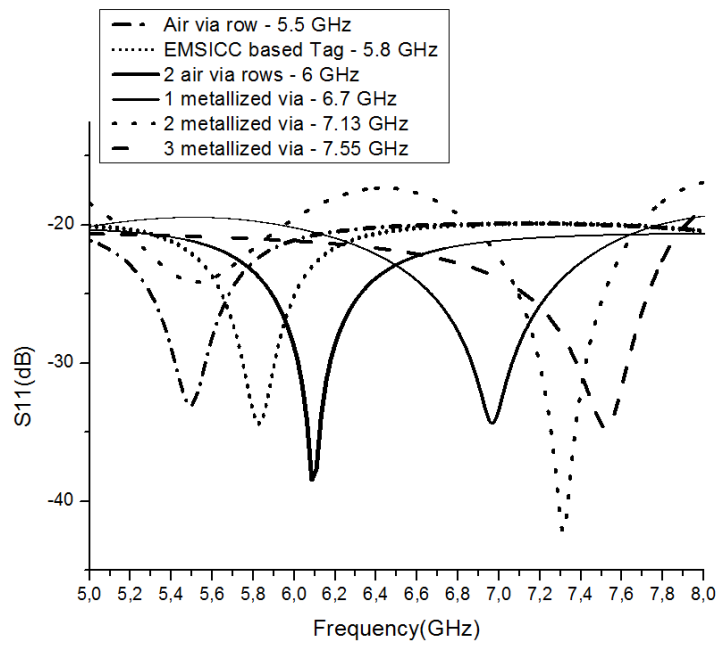

Fig. 13. The chipless tag response for six different frequencies.

The interrogator antenna and tags were separated by a distance of $4 \mathrm{~cm}$. It can be seen that a very good agreement is achieved between the measured results of the encoding area 'EMSICC' and the whole tag structure. Figure 13 shows the tag response which is verified for 6 different frequencies when adding the air via rows or the metalized posts.

Further, concerning the transmitted data during the test, we choose to encode using the shifting of single frequency in the band of $5 \mathrm{GHz}$ to $8 \mathrm{GHz}$, as previously detailed. So, in each prototype test, we should find a single frequency in the desired band.

In our case, it is clearly seen that there is a parasite frequency at $5.4 \mathrm{GHz}$ in the test of the tag with two metalized vias. It can be caused by the manual via metallization, or also by the substrate permittivity change after realiza- tion. And certainly, the improvement of metallization and test conditions will lead automatically to the absence of the parasite minimum at frequency $5.4 \mathrm{GHz}$ and the appearance of the desired resonant peak only.

\section{Comparative Analysis}

The RFID chipless tag EMSICC-based offers the advantages of a low weight, a reduced size, a simple frequency, and a shifting technique which allows a frequency shift from 5 to $8 \mathrm{GHz}$. The FR4 substrate with $\varepsilon_{\mathrm{r}}=4.6$, a loss tangent of 0.025 , and thickness of $h=0.8 \mathrm{~mm}$, yields good results as well as a good agreement between the simulated and the measured results. A comparison between the proposed tag and the existing SIW-based tag is presented in Tab. 2. It can be seen that an improved essay is presented as far as the tag surface is concerned. The technique used is a recent application in the chipless technology $(1 / 8$ of SICC surface). Further, the UWB antenna, which is the second parts of the tag, is a novel bowtie meander antenna. Also, the encoding principle in [21] and [22] is based respectively on the missing air via in the substrate and the added metalized posts to ensure the shifting encoding. In this paper, we exploit the two techniques at same time, proving that we can find many frequencies and that each frequency defines an encoding state in a reduced sub-band of UWB. The comparison shows that our EMSICC-based chipless tag gives reasonable results, a compact size and an original shape. For the purpose of obtaining a better performance and an appropriate size, an immense contribution is still to be done in order to more apply the SIW technology in RFID chipless and get more improved performance.

\section{Conclusion}

In this paper, a new RFID chipless tag design based on an EMSICC is presented. First, a SICC was studied and simulated on the Ansoft HFSS. The SICC was then bisected into two parts to obtain the HMSICC, into four parts to obtain the QMSICC and into eight parts to obtain the wanted shape which is the EMSICC. Besides, the cavity was associated to bowtie-meander-shaped antenna forming the complete chipless tag. A very good agreement is obtained between the results. The test of the chipless system validates our design and shows that a compact chipless tag is realized with a dimension area of $(4.9 \times 1.05) \mathrm{cm}^{2}$, and a quality factor equal to 264 .

\begin{tabular}{|c|c|c|c|c|c|c|}
\hline $\begin{array}{c}\text { Chipless TAG based } \\
\text { SIW }\end{array}$ & $\begin{array}{c}\text { Tag Size } \\
\left.\mathbf{( m m}^{2}\right)\end{array}$ & $\begin{array}{c}\text { Area of encoding } \\
\left.\text { cavity } \mathbf{( m m}^{\mathbf{2}}\right)\end{array}$ & $\begin{array}{c}\text { Principle } \\
\text { of Encoding }\end{array}$ & $\begin{array}{c}\text { Encoding } \\
\text { technique }\end{array}$ & $\begin{array}{c}\text { Operation } \\
\text { frequency (GHz) }\end{array}$ & $\begin{array}{c}\text { Substrate } \\
\text { Thickness (mm) }\end{array}$ \\
\hline $\begin{array}{c}\text { Rectangular cavity } \\
\text { based tag [20] }\end{array}$ & $15 \times 30$ & $10.5 \times 10.5$ & Air via & Frequency shifting & $10.5-11$ & 1.524 \\
\hline $\begin{array}{c}\text { Rectangular cavity } \\
\text { based tag [21] }\end{array}$ & $\begin{array}{c}50 \times \\
108.5\end{array}$ & $46 \times 46$ & Metalized via & Frequency shifting & $3.1-4.8$ & 0.5 \\
\hline EMSICC based tag & $10.5 \times 49$ & $10.5 \times 17$ & $\begin{array}{c}\text { Air via and } \\
\text { Metalized via }\end{array}$ & Frequency shifting & $5-8$ & 0.8 \\
\hline
\end{tabular}

Tab. 2. Comparison between some RFID chipless tags SIW based found in the literature 


\section{References}

[1] FINKENZELLER, K. RFID Handbook. $2^{\text {nd }}$ and $3^{\text {rd }}$ ed. West Sussex (U.K.): John Wiley \& sons, 2003.

[2] DAS, R., HARROP, P. RFID Forecasts, Players and Opportunities 2011-2021. [Online]. Available: www.IdtechEx.com

[3] WENG, Y. F., CHEUNG, S. W., YUK, T. I., LIU, L. Design of chipless UWB RFID system using a CPW multi-resonator. IEEE Antennas and Propagation Magazine, 2013, vol. 55, no. 1, p. 13 to 31. DOI: 10.1109/MAP.2013.6474480

[4] TEDJINI, S., KARMAKAR, N., PERRET, E., et al. Hold the chips: Chipless technology, an alternative technique for RFID. IEEE Microwave Magazine, 2013, vol. 14, no. 5, p. 56-65. DOI: 10.1109/MMM.2013.2259393

[5] PRERADOVIC, S., BALBIN, I., KARMAKAR, N., et al. A novel chipless RFID system based on planar multiresonators for barcode replacement. In 2008 IEEE International Conference on RFID. New York (USA), 2008, p. 289-296. DOI: 10.1109/RFID.2008.4519383.

[6] GIRBAU, D., RAMOS, A., LÁZARO, A., et al. Passive wireless temperature sensor based on time-coded UWB chipless RFID tags. IEEE Transactions on Microwave Theory and Techniques, 2012, vol. 60, no. 11, p. 3623-3632. DOI: 10.1109/TMTT.2012.2213838

[7] VENA, A., PERRET, E., TEDJINI, S. Chipless RFID tag using hybrid coding technique. IEEE Transactions on Microwave Theory and Techniques, 2011, vol. 59, no. 12, p. 3356-3364. DOI: 10.1109/TMTT.2011.2171001

[8] ZOMORRODI, M., KARMAKAR, N. C. Novel MIMO-based technique for EM-imaging of chipless RFID. In 2015 IEEE MTT-S International Microwave Symposium (IMS). DOI: 10.1109/MWSYM.2015.7166720

[9] HARTMANN, C. S. A global SAW ID tag with large data capacity. In Proceedings of the IEEE Ultrasonics Symposium. Munich (Germany), Oct. 2002, p. 65-69. DOI: 10.1109/ULTSYM.2002.1193354

[10] HARTMANn, C., HARTMANN, P., BROWN, P., et al. Anticollision methods for global SAW RFID tag systems. In Proceedings of the IEEE Ultrasonics Symposium. Montréal (Canada), Aug. 2004, p. 805-808. DOI: 10.1109/ULTSYM.2004.1417859

[11] JALALY, I., ROBERTSON, I. D. RF barcodes using multiple frequency bands. In IEEE MTT-S Microwave Symposium Digest. Long Beach (CA, USA), June 2005, p. 139-141. DOI: 10.1109/MWSYM.2005.1516542

[12] JALALY, I., ROBERTSON, I. D. Capacitively tuned split microstrip resonator for RFID barcodes. In Proceedings of the 35th European Microwave Conference. Paris (France), October 4-6, 2005, vol. III. DOI: 10.1109/EUMC.2005.1610138

[13] PRERADOVIC, S., BALBIN, I., KARMAKAR, N.C. Multiresonator based chipless RFID system for low-cost item tracking. IEEE Transactions on Microwave Theory and Techniques, 2009, vol. 57, no. 5, p. 1411-1419. DOI: 10.1109/TMTT.2009.2017323

[14] PERRET, E., HAMDI, M., VENA, A., et al. RF and THz identification using a new generation of chipless RFID tags. Radioengineering, 2011, vol. 20, no. 2, p. 380-386.

[15] VENA, A., PERRET, E., TEDJINI, S. High-capacity chipless RFID tag insensitive to the polarization. IEEE Transactions on Microwave Theory and Techniques, 2011, vol. 60, no. 10, p. 4509 to 4515. DOI: $10.1109 /$ TAP.2012.2207347

[16] ATTARAN, A., RASHIDZADEH, R., MUSCEDERE, R. Chipless RFID tag using RF MEMS switch. Electronics Letters, 2014, vol. 50, no. 23 , p. 1720-1722. DOI: 10.1049/el.2014.3075

[17] NAIR, R., BARAHONA, M., BETANCOURT, D., et al. A fully printed passive chipless RFID tag for low-cost mass production. In Proceedings of the 8th European Conference on Antennas and Propagation (EuCAP 2014). The Hague (The Netherlands), 2014. DOI: 10.1109/EUCAP.2014.6902446

[18] VENA, A., PERRET, E., TEDJINI, S., et al. Design of chipless RFID tags printed on paper by flexography. IEEE Transactions on Antennas and Propagation, 2013, vol. 61, no. 12, p. 5868-5877. DOI: $10.1109 /$ TAP.2013.2281742

[19] VENA, A., PERRET, E., TEDJINI, S. A fully printable chipless RFID tag with detuning correction technique. IEEE Microwave and Wireless Components Letters, 2012, vol. 22, no. 4, p. 209 to 211. DOI: 10.1109/LMWC.2012.2188785

[20] El Matbouly, H., BOUBEKEUR, N. DOMingue, F. A novel chipless identification tag based on a Substrate Integrated Cavity Resonator. IEEE Microwave and Wireless Components Letters, 2013, vol. 23, no. 1, p. 52-54. DOI: 10.1109/LMWC.2012.2236081

[21] MOSCATO, S., MORO, R., BOZZI, M., et al. 'Chipless RFID for space applications. In Proceedings of the IEEE International Conference on Wireless for Space and Extreme Environments WISEE 2014. Noordwijk (The Neterlands), October 2014. DOI: 10.1109/WiSEE.2014.6973075

[22] BOZZI, M., GEORGIADIS, A., WU, K. Review of substrateintegrated waveguide circuits and antennas. IET Microwaves, Antennas and Propagation, 2011, vol. 5, no. 8, p. 909-920. DOI: 10.1049/iet-map.2010.0463

[23] BOZZI, M., PERREGRINI, L., WU, K., et al. Current and future research trends in substrate integrated waveguide technology. Radioengineering, 2009, vol. 18, no. 2, p. 201-2019.

[24] DESLANDES, D., WU, K. Single-substrate integration technique of planar circuits and waveguide filters. IEEE Transactions on Microwave Theory and Techniques, 2003, vol. 51, no. 2, p. 593 to 596. DOI: 10.1109/TMTT.2002.807820

[25] MAJEDI, M. S., ATTARI, A. R. Resonance antennas based on substrate integrated waveguide. IET Microwaves, Antennas and Propagation, 2015, vol. 9, no. 10, p. 1021-1027. DOI: 10.1049/iet-map.2014.0662

[26] JIN, C., LI, R., ALPHONES, A., et al. Quarter-mode substrate integrated waveguide and its application to antennas design. IEEE Transactions on Antennas and Propagation, 2013, vol. 61, no. 6, p. 2921-2928. DOI: 10.1109/TAP.2013.2250238

[27] CHEN, J.-X.., HONG, W., HAO, Z.-C., et al. Development of a low cost microwave mixer using a broadband substrate integrated waveguide (SIW) coupler. IEEE Microwave and Wireless Components Letters, 2006, vol. 16, no. 2, p. 84-86. DOI: 10.1109/LMWC.2005.863199

[28] CASSIVI Y., WU, K. Low cost microwave oscillator using substrate integrated waveguide cavity. IEEE Microwave and Wireless Components Letters, 2003, vol. 13, no. 2, p. 48-50. DOI: 10.1109/LMWC.2003.808720

[29] ECCLESTON, K. W. Corrugated substrate integrated waveguide distributed amplifier. In Proceedings of Asia-Pacific Microwave Conference APMC 2012. Kaohsiung (Taiwan), Dec. 4-7, 2012. DOI: 10.1109/APMC.2012.6421604

[30] XU, F., WU, K., ZHANG, X. Periodic leaky-wave antenna for millimeter wave applications based on substrate integrated waveguide. IEEE Transactions on Antennas and Propagation, 2010, vol. 58, no. 2, p. 340-347. DOI: 10.1109/TAP.2009.2026593.

[31] D'ORAZIO, W., KE WU, K. Substrate-integrated-Waveguide circulators suitable for millimeter-wave integration. IEEE Transactions on Microwave Theory and Techniques, 2006, vol. 54, no. 10 , p. $3675-3680$. DOI: 10.1109/TMTT.2006.882897 
[32] BALANIS, C. A. Antenna Theory Analysis and Design. 3rd ed. New York (USA): Wiley, 2005.

[33] P. JANKOWSKI-MIHUŁOWICZ, P., LICHOŃ, W., PITERA, G., et al. Determination of the material relative permittivity in the UHF band by using $\mathrm{T}$ and modified ring resonators. International Journal of Electronics and Telecommunications, 2016, vol. 62, no. 2, p. 129-134. DOI: 10.1515/eletel-2016-0017

\section{About the Authors ...}

Soumaya SAKOUHI was born in Bousalem, Tunisia. She received the degree in Electrical Engineering from the Faculty of Sciences of Tunis, Tunisia in 2013. She is currently working toward the Ph.D. degree in Electrical Engineering at the same faculty. Her main research interests include RFID chipless tags and SIW technology.

Hedi RAGGAD was born in Bengardene, Tunisia. He received his Eng. degree in Electronic Engineering from the Marne La Vallee University France, in 2007, and the Ph.D. degree from ESEO, Angers, France. His research interests include dielectric resonator antennas and passive RF devices.
Ali GHARSALLAH received the degree in Radio Frequency Engineering from the Higher School of Telecommunication of Tunis in 1986 and the Ph.D. degree in 1994 from the Engineering School of Tunis. Since 1991, he was with the Department of Physics, Faculty of Sciences of Tunis. Actually, he is a Full Professor in Electrical Engineering and Director of the Engineering studies in the Higher Ministry Education of Tunisia. His current research interests include smart antennas, array signal processing, multilayered structures and microwave integrated circuits. He has about eighty papers published in scientific journals and more than a hundred papers conferences. Professor Gharsallah supervises more than twenty thesis and fifty Masters.

Mohamed LATRACH was born in Douar ksiba, Sless, Morocco. He received his Ph.D. degree in Electronics from the University of Limoges, Limoges, France, in 1990. Presently, he is a professor of Microwave Engineering and head of the Radio \& Microwave group at ESEO, Angers, France. His field of research interest is the design of hybrid, monolithic active and passive microwave circuits, metamaterials, Left Handed Materials, antennas, wireless power transmission and their applications in RFID and communication systems, etc. 